\title{
VECTOR AR3-APP - A GOOD-PRACTICE EXAMPLE OF LEARNING WITH AUGMENTED REALITY
}

Karin Langer [karin.langer@technikum-wien.at], Stefanie Lietze [stefanie.lietze@technikumwien.at], Gerd Ch. Krizek [gerd.krizek@technikum-wien.at], Fachhochschule Technikum Wien [www.technikum-wien.at], Höchstädtplatz 6, A-1200 Vienna, Austria

\begin{abstract}
After a discussion about the possibilities and status of augmented reality in education, a good practice example of an augmented reality application is presented. This case study examines the use of an augmented reality app in higher education to support abstract STEM content, such as vectors. Based on this example, the implementation of such apps in didactic concepts and selfdirected learning will be discussed. Furthermore, aspects of integration into digital learning and teaching will be addressed.
\end{abstract}

\section{German Abstract}

Nach einem Überblick über die Möglichkeiten und den Status von Augmented Reality im Bildungswesen wird ein Good-Practice-Beispiel einer Augmented-Reality-Anwendung vorgestellt. Dieses Fallbeispiel untersucht anhand dieser App die Verwendung von Augmented Reality in der Hochschulbildung zur Unterstützung abstrakter STEM-Inhalte, wie z.B. Vektoren. Mittels dieses Beispiels wird die Implementierung solcher Apps in didaktische Konzepte sowie ihr Nutzen unter dem Gesichtspunkt des selbstgesteuerten Lernens diskutiert. Darüber hinaus werden Aspekte der Einbindung in das digitale Lernen und Lehren adressiert.

Keywords: Mathematics; e-learning; augmented reality, app based learning, mobile learning, eDidactics

With the development of digital learning technologies and application, the media that are employed in teaching and learning mathematics at university levels started to change: There has been a noticeable shift towards digital tools and resources which also allow "different forms of interactions between user and medium" (Ruthven, 2018; p.261), for example by providing instantaneous feedback. Augmented reality (AR) emerged as one of the top educational trends as the technology became easily accessible via consumer grade devices such as smartphones and tablet computers (Yuen, Yaoyuneyong, \& Johnson, 2011; p.120). Great hopes were placed in the AR technology: Not only did it offer students the opportunity to view the teaching content from different angles (Kerawalla, Luckin, Selijefot, \& Woolard, 2006), it also supposedly provided the opportunity to intensify the cooperation between students and between teachers and students (Billinghurst, 2002). It was also believed that this would stimulate the creativity of the students (Klopfer \& Yoon, 2004) who would be enabled to "see the world around them in new ways and 
engage with realistic issues in a context with which the students are already connected." (Klopfer \& Sheldon, 2010; p.86).

Although the use of augmented reality (AR) and virtual reality (VR) apps and software in secondary education has repeatedly been tested and documented (e.g. Osberg, 1997; Rizzo et al., 2000 with regard to students with learning disabilities), only relatively few research and development teams have explored how "mobile, context-aware AR could be used to enhance K-20 teaching and learning" (Dunleavy \& Dede, 2014; p.8) (the education descriptor K-20 denotes education levels from Kindergarten to graduate degree. (Wang, 2013)); there are only a few studies and a large-scale field experiment to test the effect of $\mathrm{AR}$ on learning performance in an informal learning environment (Sommerauer \& Müller, 2014).

"With an increasing amount of digital applications and Web 2.0 tools readily available, technology has a key role in the 21st century classroom" (Estapa \& Nadolny, 2015; p.40). AR is "a virtual reality variation in which the user can see the real world with virtual objects mixed or superimposed upon it. In contrast to virtual reality, AR does not replace the real environment; rather, AR uses the real environment as a background. The final result is a file with data, static images, or a dynamic 3D virtual model superimposed onto a real-time video of the environment. This scene is shown to the user via a computer screen or other device, such as a projector, digital board, special glasses, smartphone, or tablet.” (Fonseca, Martí, Redondo, Navarro, \& Sánchez, 2013; p.435). For further studies about AR technology and education see also Milgram, Takemura, Utsumi, and Kishino (1995), Carvalho and Lemos (2014), Wu, Lee, Chang, and Liang (2013) and Martin-Gutierrez, Guinters, and Perez-Lopez (2012). AR is an interactive technology whose contents can be watched and worked with in real-time (Zhou, Duh, \& Billinghurst, 2008; p.193).

While AR has increasingly been used in recent years for the presentation of basic school subjects of a more abstract nature such as Mathematics and Physics (see for example Lin, Chen, and Chang, 2015, and Estapa and Nadolny, 2015), there is still a lack of corresponding offers for the higher education sector.

Besides technical possibilities, the embedding in learning scenarios is key to success for every learning tool. The success of a learning scenario depends heavily on the commitment of the teachers. They need to receive training and support for the software and the associated learning techniques so that they can provide students with the best possible support (Fonseca, Martí, Redondo, Navarro, \& Sánchez, 2013; p.435).

The vector app project originated from the university lecturers' demand for additional digital resources in order to lift complex mathematical contents in the field of vector computation in three dimensions from the limitations of the two-dimensional representation and thus be able to convey it adequately. In addition, the project meets the students' needs for quality-assured, freely available learning materials. In 2019, the Teaching and Learning Centre and the Department of Applied Mathematics and Physics at the University of Applied Sciences Technikum Vienna developed the "Vektor AR3"-app, which demonstrates that AR as a technology is suitable for providing didactically meaningful support for basic STEM subjects in higher education. For this app, vector 
analysis was chosen as a topic, because three-dimensional abstract concepts such as vectors and linear algebra are often difficult to grasp for pupils and students alike. The decision for an AR representation instead of a purely graphic solution as learning tool for the students was based on two fundamental assumptions:

First, the basic understanding of three-dimensional aspects is facilitated by the reference to reality (Quintero, Salinas, González-Mendívil, \& Ramírez, 2015; p.302). The use of AR makes it possible to switch between different, interactively linked representations of the mathematical content in order to facilitate better understanding (Hegedus, Laborde, Brady, Dalton, Siller, Tabach, Trgalova, \& Armella, 2017; p.22). For sciences such as Mathematics and Physics as well as Engineering, spatial ability is a crucial skill (Quintero, Salinas, González-Mendívil, \& Ramírez, 2015; p.301). Kaufman and Schmalstieg (2003) identify five elements that this ability consists of: spatial perception, spatial visualization, mental rotations, spatial relations and spatial orientation. Given that these competencies are taken for granted in the subsequent course of education, additional hurdles in the development of constructive content and competencies arise. Traditionally, these elements are taught in an analogue way, meaning that students are required to analyse and study pictorial and orthogonal views on a blackboard or on paper. This can impede the understanding the concept of space; also, the possibility for students to interact with their subject is limited as it can only be drawn or calculated but not for example be viewed from different angles. The development of spatial ability can be supported by the use of motor activity to help comprehend the concept of space (Onyancha, Derov, \& Kinsey, 2009). With the help of AR, objects can be observed and (de)constructed from various different visual angles and positions (Quintero, Salinas, González-Mendívil, \& Ramírez, 2015; p.302). Real-world depiction of vectors enables real-time interaction with these abstract elements (Sala, 2016; p.2). The experimental manipulation of all relevant factors such as coordinate system, direction, etc. helps to understand the basic concept of vectors as well how they work.

Interactive visualisation (Preuß \& Kauffeld, 2019; p.404) with the help of AR can not only help students to get a better grasp of abstract matters. AR also "allows for collaborative experiences in a real scene” (Fonseca, Martí, Redondo, Navarro, \& Sánchez, 2013; p.436).

Second, the app was chosen as a as learning tool due to its strong playful character caused by its reality reference (Quintero, Salinas, González-Mendívil, \& Ramírez, 2015; p.302). The "Vektor AR3"-app allows for students to access Mathematics as part of the digital culture they are already used to, favouring visual perception as an additional approach to the standard depiction of algebraic symbols (Salinas, 2017). Being what Marc Prensky defined as "Digital Natives" (Prensky, 2001) the students are used to technology pervading all aspects of their daily lives. The interactive nature of the application stimulates more active participation and collaboration of students (Mladenović, Kuvač, \& Štula, 2012; pp.2-3). This hybrid learning arrangement (Kerres, 2018; p. 95) motivated test persons to deal with the subject matter independently and thus promoted interest in content as well as self-regulated learning. As described in the so-called discovery learning approach, students are encouraged to construct their knowledge by experimenting and also to deduce principles and rules from their interaction with the subject matter (Bruner, 1961; Ibáñez \& 
Delgado-Kloss, 2018). "Working with a collaborative interface, interactive discussions of the projects, and the capacity to generate physical and digital expositions are activities that have generated an active student, with significant improvements in spatial, research and interaction skills." (Fonseca, Martí, Redondo, Navarro, \& Sánchez, 2013; p.443) In a Taiwanese study from 2015 , it is reported that in thirteen to fourteen-year-old students, the use of information technology for the teaching of geometry not only enhances interest, but also helps them to understand abstract mathematical concepts, particularly those whose spatial sense is not as well developed as in others (Lin, Chen, \& Chang, 2015; pp.800-801). The use of AR guarantees that each student can individually access the content in different environments at different time. With learning centred on the individual, students are encouraged to experiment and explore the abstract subject matter, observing and interpreting it in real time (Coimbra, Cardoso, \& Mateus, 2015; p.333).

In order to implement the goals of the National Strategy for the Social Dimension in Higher Education (BMWFW, 2017), the Teaching and Learning Centre (TLC) was implemented at the University for Applied Sciences Technikum Vienna as a service centre for all those involved in education. It supports prospective and current students by means of inclusive measures that are suitable for compensating for disadvantages caused by diversity. With the "Bridging Diversity"program, the consistent implementation of the university's "Gender Mainstreaming \& Managing Diversity" strategy from 2016 is pursued. For this purpose, a broad repertoire of measures has been (and is being) developed and implemented, which can be used individually or combined according to individual needs (Lietze, Brezowar, \& Krizek, 2019). This considers the fact that, on the one hand, students have different levels of mathematical knowledge. Some students at the University of Applied Sciences Technikum Vienna come to the university only after a longer period of employment, qualify through the qualification examination for university entrance or through subsidized pre-study programs. What they all have in common is that they must learn or reactivate independent learning.

On the other hand, the students show a vastly different motivation to learn, which depends on various factors. These include among others their individual interest in the field, previous knowledge (Rach, 2014; pp.216-218), persistence, social background, and their varying degrees of knowledge in the mathematical field (Sullivan, Mousley, \& Zevenbergen, 2004; pp.257-258).

Many didactic inclusion activities target primarily female students (ITU, 2020a), whereas the TLC's "Bridging Diversity"-activities address every member of the university's heterogeneous group of students. That means establishing a learning culture that takes into account no only the diverse biographic, educational and cultural backgrounds, but also factors like age, varying language skills as well as disabilities and chronic illnesses. "Digital inclusion means ensuring all people have an equal opportunity to become empowered through ICTs and be part of digital society. To achieve this goal ICTs should be accessible, which means they are designed to respect the needs of all people - including those with disabilities. In doing so, we can ensure that future smart communities will be fully accessible to everyone and that digital societies benefit all people equally." (ITU, 2020b). In fact, some subject areas, such as STEM or social sciences, are even less likely to attract all genders or minorities than other subjects (Furner \& Gonzalez-DeHass, 2011; 
Chestnut, Lei, Leslie, \& Cimpian, 2018). In these fields, it is the responsibility of higher education institutions to identify intersectional diversity factors (UNTIL, 2019) and lower barriers for the underrepresented groups to take up these subjects, to provide a gender and diversity adequate education, and to offer intersectional services to prevent dropout.

In cooperation with experts of digital teaching and implementations, the team developed and implemented an accompanying teaching concept for embedding the vector app in a learning arrangement (for an overview of learning arrangements see Chao and Chang, 2018). This didactic AR teaching concept is aligned with the in-house e-learning strategy. It is intended for students and lecturers of mathematical, technical and natural science studies (mainly on the bachelor level, but also useful to refresh basic competencies for master programmes) in curricular and noncurricular programs. In addition, it targets secondary school pupils and teachers. As part of the University's school cooperations, the application is introduced to teachers and students of partner schools. Both teachers and students were presented with milestones and intermediate stages of development. Based on their feedback, further developments were designed and the corresponding scenarios selected.

Based on the teachers' and students' requirements, an app-supported teaching concept was developed, which makes the fundamentals of linear algebra and vector analysis comprehensible through three-dimensional imaging. After analysing different presentation approaches as well as suitable media, mobile devices were selected due to their wide availability. With this, a higher learning autonomy is granted (with regard to the positive effects of learning autonomy, see Rach, 2014) and the concept of mobile learning, which has rarely been used in higher education, is added as an extra benefit to this approach (Kaliisa, Palmer, \& Miller, 2017). In order to enable students to actively produce content themselves, it is necessary to transfer teaching from a traditional learning environment with frontal teaching to an extended learning environment (Fonseca, Martí, Redondo, Navarro, \& Sánchez, 2013; p.435). For a similar but much more complex approach (requiring the hardware Kinect) see also Martin-Gonzales, Chi-Poot, and Uc-Cetina (2016). The "Vektor AR3"-app allows the hands-on use of AR in lecture halls and expands on existing methods and technologies in the field of digital teaching, such as online elements in courses (e.g. e-tests) or online lecture recordings. AR is a useful technology in its own right but works most effectively when embedded in learning arrangements tailored to its application. In such an arrangement the student is guided towards establishing a coordinate system, within which vectors may be created and manipulated. This fosters a basic understanding of the individual components through a learning by doing approach supplemented by explanatory comments, both for teachers and learners.

The following contents of the vector calculation are made accessible interactively in the "Vektor AR3"-app:

- Cartesian-based vectors and their components;

- Vectors on a skewed base and their components;

- Scalar product and geometric interpretation; 
- Cross product and geometric interpretation;

- Area normal vectors and vector fields.

After a demonstration by lecturers in class, the application will be made available to students for self-study or tasks completion. This will bridge the gap between a predominantly theoretical approach, which has so far been the norm, and a style of learning focused on the practical application of learning content. This is achieved by means of visual interactive learning elements and three-dimensional imaging, supplemented with a suitable classroom teaching concept. Realworld depiction of vectors enables interaction with these abstract elements. The experimental as well as targeted manipulation of all relevant factors such as coordinate system, basis, orientation, components, etc. helps to develop a basic understanding of the functioning of these and of the basic concept of vectors. The app allows to divide the learning content into small information units, which can then be structured and queried. The flexibility of learning independently of time and place is conducive to the learning and processing mechanisms of the students; problem-oriented action is supported, as is self-regulated learning.

Here is an example of two tasks that students can work through with the help of the app (Robimo, 2019):

\section{Task 1 - Creating a vector and reading its components}

The first task is to create a random vector in vector app and read its components. In the start screen, select the first menu item "Cartesian and Skew Coordinate System" and place the coordinate system as shown in Figure 1a. Now you can check or change the individual axes via a tab of your own. In this first task, we are satisfied with the fact that it is a Cartesian coordinate system whose axes correspond to the standard base unit vectors.

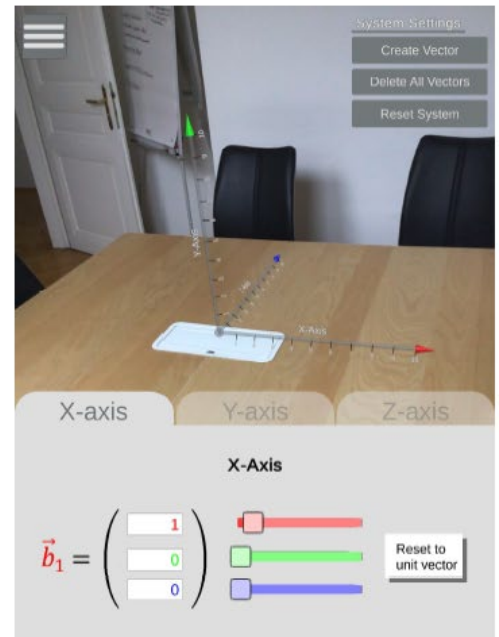

a) Information for $\mathrm{x}$-axis

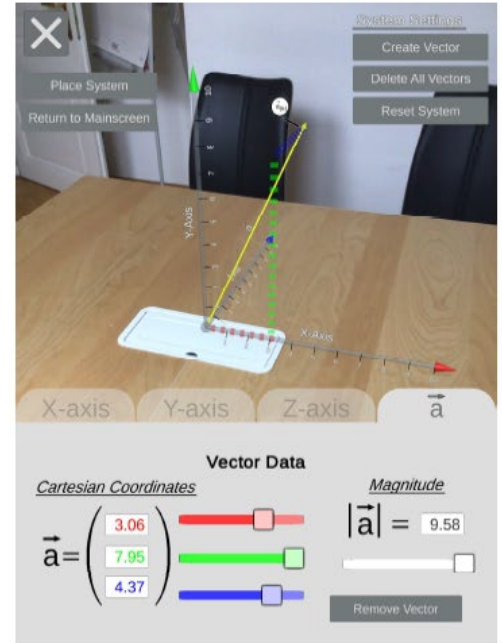

b) Random vector

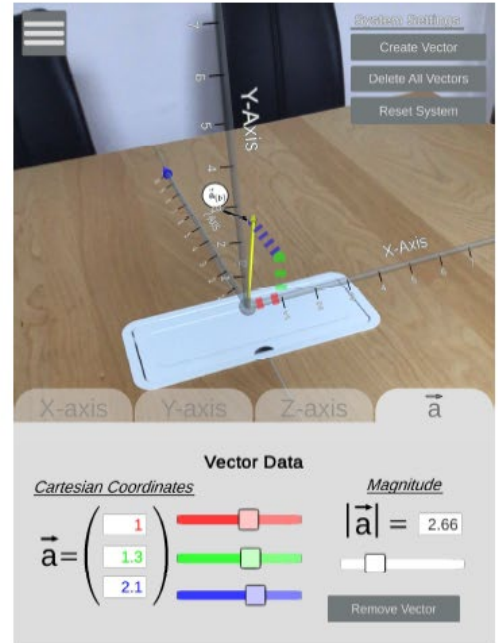

c) Manually changed vector

Figure 1: Creating a vector and reading its components

In the next step, you can create a random vector using the button "Create Vector" in the upper right-hand corner of the image. Figure $1 \mathrm{~b}$ shows a randomly generated vector $\vec{a}$ whose cartesian coordinates can be read directly in the tab of the vector. 
This vector reads

$$
\vec{a}=3.06 \cdot \vec{e}_{x}+7.95 \cdot \vec{e}_{y}+4.37 \cdot \vec{e}_{z}
$$

or as a column vector in the Cartesian base

$$
\vec{a}=\left(\begin{array}{l}
3.06 \\
7.95 \\
4.37
\end{array}\right)
$$

with the length (magnitude) $|\vec{a}|=9.58$ and the basis (see figure 1a for the x-axis)

$$
\vec{e}_{x}=\left(\begin{array}{l}
1 \\
0 \\
0
\end{array}\right), \vec{e}_{y}=\left(\begin{array}{l}
0 \\
1 \\
0
\end{array}\right), \vec{e}_{z}=\left(\begin{array}{l}
0 \\
0 \\
1
\end{array}\right)
$$

each with the length $\left|\vec{e}_{i}\right|=1$ for $i=x, y, z$.

Up to three different vectors can be created at the same time, or the existing vectors can be deleted using the "Delete All Vectors" button.

Tip: Vectors can also be edited. For example, you can change the length of the vector using the text box or the white slider in Figure 1b, without changing the direction of the vector. The direction of the vector can also be changed manually using the coloured text fields or sliders of the vector. Figure $1 \mathrm{c}$ shows a vector that was manually adjusted to the values

$$
\vec{a}=\left(\begin{array}{c}
1 \\
1.3 \\
2.1
\end{array}\right)
$$

with the length $|\vec{a}|=2.66$.

Cartesian basis - task assignment for students: Students are given the Cartesian coordinates of a vector $\vec{a}$ and are initially not allowed to use the app. Now they have to draw this vector on paper in a three-dimensional coordinate system and calculate its length $|\vec{a}|$. When they are finished, students can compare their results with the output in the app.

\section{Task 2 - Vector fields and (surface) normal vectors}

This task differs from the first four tasks mainly in that it represents a coordinate system with a three-dimensional function $F(x, y)=f(x) \cdot g(y)$, which can be generated by an appropriate selection of $f(x)$ and $g(y)$. Via the menu item surface normal vector, the outline (box) of a coordinate system can be placed. Afterwards, the functions $f(x)$ and $g(y)$ are selected from three possible presets and the function $F(x, y)=f(x) \cdot g(y)$ is displayed within the box. Figure 2 shows all the corresponding steps. 


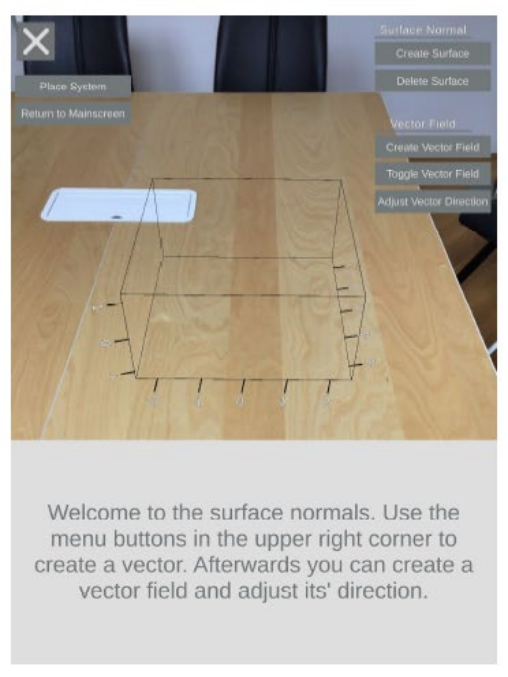

a) Coordinates box
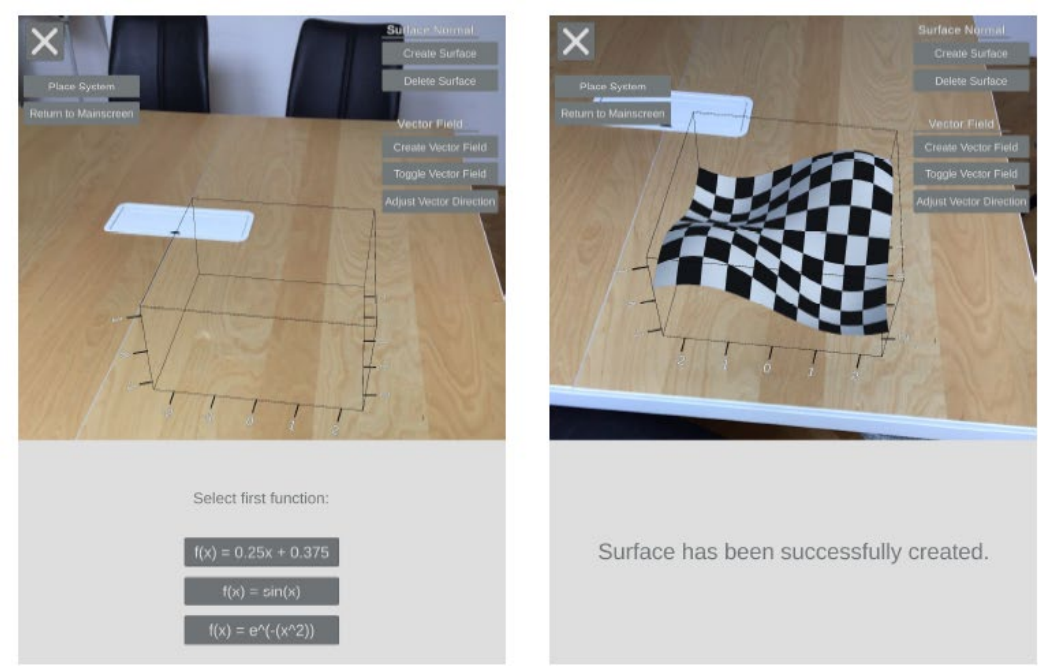

b) Selection of $f(x)$ and $g(y) \quad$ c) $F(x, y)=f(x) \cdot g(y)$

Figure 2: Creating the three-dimensional function $F(x, y)$

The function $F(x, y)=f(x) \cdot g(y)$ can be generated by selecting $f(x)$ and $g(y)$. The options predefined in vector app are:

a) $f(x)=0.25 x+0.375$

b) $f(x)=\sin (x)$

c) $f(x)=e^{-x^{2}}$

The same selection applies to $g(y)$. With the combination of these three functions, a total of nine surfaces can be created. Figure 2 c shows an example of $f(x)=\sin (x)$ and $g(y)=\sin (x)$.

Creating a vector field: Now you can use the button "Create Vector Field" to create a linear vector field, which by default is defined as

$$
\vec{v}=\left(\begin{array}{l}
0 \\
1 \\
0
\end{array}\right)
$$

In the points $P_{i}(x, y, F(x, y))$ but can be manipulated manually with the button "Adjust Vector Direction". The example in Figure 3a shows a vector field of vectors of length 1 with the direction

$$
\vec{v}=\frac{1}{\sqrt{3}}\left(\begin{array}{l}
1 \\
1 \\
1
\end{array}\right)
$$

Creating a (surface) normal vector: To create a normal vector, click on the surface of the function. With a curved surface (as in our example), the normal vector for the function $F(x, y)$ at point $P=$ $\left(x_{0}, y_{0}\right)$ is mathematically the normal vector of the tangent plane at this point.

The tangential plane is the area that the function $F(x, y)$ best approximates in the vicinity of the point $P$. 


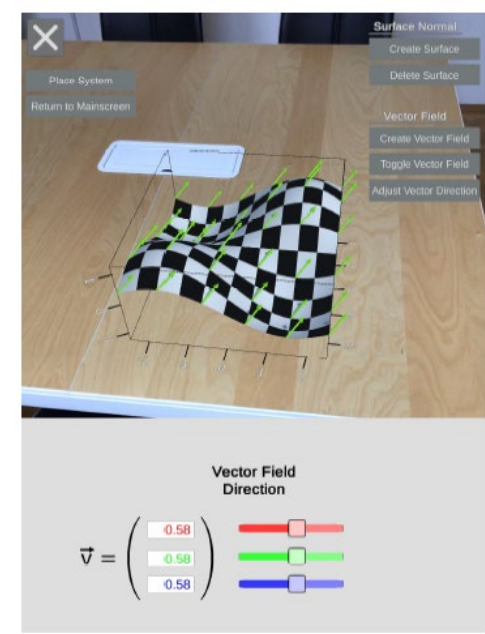

a) Vector field $\vec{v}=\frac{1}{\sqrt{3}}(1 ; 1 ; 1)$

Figure 3: Vector field and normal vector

Tip: The scalar product $\vec{n} \cdot \vec{v}$ between the normal vector $\left(\vec{n}_{0}\right)$ and the vector $\vec{v}$ is formed and displayed for each point touched $\left(x_{0}, y_{0}, F\left(x_{0}, y_{0}\right)\right)$. Both vectors and the scalar product are displayed.

(Surface-)Normal Vectors - A Task for Students: The two functions $f(x)$ and $g(y)$ as well as the direction of the vector field are given to students. In addition, individual concrete points are specified for which the normal vector or the scalar product between vector field and normal vector is first to be calculated manually. Then the calculated values can be checked with the app.

Here is an example for the two functions $f(x)=\sin (x)$ and $g(y)=\sin (x)$, the concrete point $P=\left(x_{0}, y_{0}\right)=(-1,2)$ and the vector field $\vec{v}$ from Figure 3a: The results of the partial derivatives are $F_{x}(x, y)=\cos (x) \cdot \sin (y)=0,4913$ and $F_{y}(x, y)=\cdot \sin \quad \cos (y)=0.3502$, respectively, resulting in a normal vector $\vec{n}$ of

$$
\overrightarrow{n_{1}}=\left(\begin{array}{c}
-0.4207 \\
-0.2998 \\
0.8562
\end{array}\right)
$$

The next step is to calculate the scalar product between this normal vector and the vector field. The scalar product $\vec{n} \cdot \vec{v}$ can be calculated as follows

$$
\vec{n} \cdot \vec{v}=(-0.4207 \cdot 0.5774-0.2998 \cdot 0.5774+0.8562 \cdot 0.5774)=0.0805
$$

Particularly noteworthy is the development of a low threshold open educational resource for the augmented presentation of abstract basic content at university level. The project result is deliberately designed as an Open Educational Resource (OER). This considers the responsibility for transferring knowledge and developments from the university to the general public. The basic nature of the content and the use of English as a scientific language make the application internationally interesting for different educational levels and disciplines. In order to provide the vector app for all students as open learning resource, it is compatible with all common operating systems. The app is available for AR-able phones under the name "Vektor AR3 by FHTW" via the 
popular app stores. Special head-mounted displays (VR glasses) or additional modifications for smartphones (such as Google Cardboard or Gear VR) are not required. The technical implementation was carried out with VRSoft GmbH (senselab.io). Following the Open Access Policy for Scientific Information of the European Union, the application is made available to the general public free of charge and unrestricted to other institutions and individuals. The app is therefore available for private as well as institutional use and can be employed in the context of self-study or embedded in the didactic structure of an educational setting. Every expert is free to develop further augmented reality content and application scenarios in cooperation with the executing project partner based on the existing one. Thus, in addition to an example of good practice, the project also provides a technical framework for further developments.

The development of the app is a good practice example of illustrating abstract mathematical content with the help of augmented reality, therefore acting according to the paradigm shift necessary to answer the students' and teachers' need for a more innovative way of teaching and learning STEM subjects. This app is intended to serve as inspiration as well as a technical basis for the development of further comparable scenarios in Mathematics, Physics and Engineering.

Mathematical augmented reality content at university level represents an innovation that can set significant impulses for the digitalization of teaching. Embedding in a didactic concept for classroom use completes the whole as a learning arrangement. Therefore, the possibility of more up-to-date and interactive (high) school didactics is worth mentioning. The connection of a practical learning-by-doing approach under guidance with the possibility of exploring the teaching material independently and repeatedly, anytime and anywhere, and examining and deepening the acquired competences is an essential aspect of mobile learning. Although mobile learning was already identified as a logical next step in a digitalized teaching and learning culture a few years ago, the practical implementation still lags behind. Thus, this project represents another small step in closing the gap between theory and practice and reaches a milestone in the development of mobile educational resources in higher education. As such, it motivates the development of further applications and programs in topics that have been neglected in digitalization so far.

The guided set-up of coordinate systems as well as manipulation of vectors promotes a basic understanding of the individual components through learning by doing with supplementary explanation. In addition, the app offers the opportunity to experiment with the components of the content independently and at any time in order to support the deep understanding of the issue. Therefore, the students not only acquire basic skills necessary for the further course of their education, but also develop a better grasp of abstract mathematical elements. In the short and long term, the use of such apps in the teaching context will encourage teachers and students to actively engage with digital learning material.

The "Vektor AR3"-app has been rolled out in winter semester 2019/2020, but due to Covid-19 and its impact on teaching and learning organisation, the evaluation of the acceptance by the target groups has been postponed. . The feedback of the test persons from the different target groups was constructively critical and helped to enhance the previous versions. Especially with regard to the 
current version the feedback was consistently positive. The app has recently won the eLearning AWARD 2020 in the category "University" and the International eLearning Awards (IELA) 2020, category "Mobile Learning”.

\section{References}

1. Billinghurst, M. (2002). Augmented Reality in Education. New Horizons for Learning, December 2002. Retrieved from http://solomonalexis.com/downloads/ar_edu.pdf

2. Bruner, J. S. (1961). The act of discovery. Harvard Educational Review, 31(1), 21-32.

3. Carvalho, C. V. de Alencar, \& Lemos, B.M. (2014). Possibilities of Augmented Reality Use in Mathematics Aiming at a Meaningful Learning. Creative Education, 5, 690-700. doi:10.4236/ce.2014.59081

4. Chao, W., \& Chang, R. (2018). Using Augmented Reality to enhance and Engage Students in Learning Mathematics. Advances in Social Sciences Research Journal, 5(12), 455-464. doi:10.14738/assrj.512.5900

5. Chestnut, E. K., Lei, R. F., Leslie, S. J., \& Cimpian, A. (2018). The myth that only brilliant people are good at math and its implications for diversity. Education Sciences, 8(2), 65.

6. Coimbra, T., Cardoso, T., \& Mateus, A. (2015). Augmented Reality: An Enhancer for Higher Education Students in Math's Learning? Procedia Computer Science, 67, 332-39. doi:10.1016/j.procs.2015.09.277

7. Estapa, A., \& Nadolny, L. (2015). The Effect of an Augmented Reality Enhanced Mathematics Lesson on Student Achievement and Motivation. Journal of STEM Education: Innovations and Research, 16(3), 40-48.

8. Fonseca D., Martí, N., Redondo, E., Navarro, I., \& Sánchez, A. (2013). Relationship between student profile, tool use, participation, and academic performance with the use of Augmented Reality technology for visualized architecture models. Computers in Human Behavior, 31, 434445. doi:10.1016/j.chb.2013.03.006

9. Furner, J.M., \& Gonzalez-DeHass, A. (2011). How do students' mastery and performance goals relate to math anxiety? Eurasia Journal of Mathematics, Science and Technology Education, 7(4), 227-242. https://doi.org/10.12973/ejmste/75209

10. Hegedus, S., Laborde, C., Brady, C., Dalton, S., Siller, H.-S., Tabach, M., Trgalova, J., \& Armella, L. (2017). Uses of Technology in Upper Secondary Mathematics Education. Springeropen.

11. Ibáñez, M.-B, \& Delgado-Kloos, C. (2018). Augmented Reality for STEM Learning: A Systematic Review. Computers \& Education, 123, 109-23. doi:10.1016/j.compedu.2018.05.002

12. ITU (2020a). EQUALS Gender Digital Inclusion Map. Retrieved from https://www.itu.int/en/action/gender-equality/Pages/equalsGDImap.aspx

13. ITU (2020b). About the ITU-D Digital Inclusion Programme. Retrieved from https://www.itu.int/en/ITU-D/Digital-Inclusion/Pages/about.aspx 
14. Kaliisa, R., Palmer, E., \& Miller, J. (2017). Mobile learning in higher education: A comparative analysis of developed and developing country contexts. British Journal of Educational Technology, 50(2), 1-16. doi:10.1111/bjet.12583

15. Kaufmann, H., \& Schmalstieg, D. (2003). Mathematics and Geometry Education with Collaborative Augmented Reality. Proceedings of SIGGRAPH 2002 - Conference Abstracts and Applications, 37-41.

16. Kellems R. O., Eichelberger C., Cacciatore G., Jensen, M., Frazier, B., Simons, K., \& Zaru, M. (2020). Using Video-Based Instruction via Augmented Reality to Teach Mathematics to Middle School Students with Learning Disabilities. Journal of Learning Disabilities, 53(4), 277291. doi:10.1177/0022219420906452

17. Kerawalla, L., Luckin, R., Selijefot, S., \& Woolard, A. (2006). Making it real: Exploring the potential of augmented reality for teaching primary school science. Virtual Reality, 10(3-4), 163-174.

18. Kerres, M. (2018). Mediendidaktik: Konzeption und Entwicklung digitaler Lernangebote. De Gruyter.

19. Klopfer, E., \& Yoon, S. (2004). Developing games and simulations for today and tomorrow's tech savvy youth. TechTrends, 49(3), 41-49.

20. Klopfer, E., \& Sheldon, J. (2010). Augmenting your own reality: Student authoring of sciencebased augmented reality games. New Directions for Youth Development, 2010(128), 85-94.

21. Lietze, S., Brezowar, G., \& Krizek, G. (2019). Bridging Diversity - A Good Practice Example of Student Support. Proceedings of the INTED2019 Conference, $11^{\text {th }}-13^{\text {th }}$ March 2019, Valencia, Spain, 498-502. ISBN: 978-84-09-08619-1

22. Lin, H.K., Chen M., \& Chang, C (2015). Assessing the effectiveness of learning solid geometry by using an augmented reality-assisted learning system. Interactive Learning Environments, 23(6), 799-810. doi:10.1080/10494820.2013.817435

23. Martin-Gonzalez, A., Chi-Poot, A. \& Uc-Cetina, V. (2016). Usability Evaluation of an Augmented Reality System for Teaching Euclidean Vectors. Innovations in Education and Teaching International, 53(6), 627-636. doi:10.1080/14703297.2015.1108856

24. Martin-Gutierrez, J., Ginters, E., \& Perez-Lopez, D. (2012). Improving Strategy of SelfLearning in Engineering: Laboratories with Augmented Reality. Procedia - Social and Behavioral Sciences, 5, 832-839. doi:10.1016/j.sbspro.2012.08.249

25. Milgram, P., Takemura, H., Utsumi, A., \& Kishino, F. (1995). Augmented reality: A class of displays on the reality-virtuality continuum. Telemanipulator and Telepresence Technologies, 2351, 282-292. doi:10.1117/12.197321

26. Mladenović, S., Kuvač, H., \& Štula, M. (2012). Virtual Learning Environment. In Information Resources Management Association (Ed.), Virtual Learning Environments: Concepts, Methodologies, Tools and Applications (Vol. 1, pp. 1-16). IGI Global. 
27. Onyancha, R. M., Derov, M., \& Kinsey, B.L. (2009). Improvements in spatial ability as a result of targeted training and computer-aided design software use: Analyses of object geometries and rotation types. Journal of Engineering Education, 98(2), 157-67. doi:10.1002/j.21689830.2009.tb01014.x

28. Osberg, K. (1997). Spatial cognition in the virtual environment, Technical R-97-18. Seattle: HITLab. Retrieved from http://www.hitl.washington.edu/projects/education/puzzle/spatialcognition.html

29. Prensky, M. (2001). Digital Natives, Digital Immigrants. On the Horizon, 9(5), 1-6. Retrieved from http://www.marcprensky.com/writing/Prensky\%20\%20Digital\%20Natives,\%20Digital\%20Immigrants\%20-\%20Part1.pdf

30. Preuß, P., \& Kauffeld, S. (2019). Visualisierung in der Lehre. In S. Kauffeld, \& J. Othmer (Eds.), Handbuch Innovative Lehre (pp. 403-408). Springer. Retrieved from https://books.google.at/books?id=g_-

ZDwAAQBAJ\&pg $=$ PR6\&dq $=$ Handbuch + Innovative + Lehre \&hl $=$ de\&sa $=$ X\&ved $=0$ ahUKEwj w7KCYufHmAhUEMewKHekmAEUQ6AEIKTAA\#v=onepage \&q=Handbuch\%20Innovativ e\%20Lehre\&f=false

31. Quintero, E., Salinas, P., González-Mendívil, E., \& Ramírez, H. (2015). Augmented Reality App for Calculus: A Proposal for the Development of Spatial Visualization. Procedia Computer Science, 75, 301-305. doi:10.1016/j.procs.2015.12.251

32. Robimo GmbH. (2019). AR3 - Mathematik (be)greifbar. Lehrkonzept für die AR Applikation Vektor AR3 [Unpublished manuscript]. Vienna.

33. Rach, S. (2014). Charakteristika von Lehr-Lern-Prozessen im Mathematikstudium: Bedingungsfaktoren für den Studienerfolg im ersten Semester. Münster; New York: Waxmann Verlag.

34. Rizzo, A. A., Buckwalter, J. G., Bowerly, T., van der Zaag, C., Humphrey, L., Neumann, U., Chua, C., Kyriakakis, C., van Rooyen, \& Sisemore, D. (2000). The virtual classroom: a virtual reality environment for the assessment and rehabilitation of attention deficits. CyberPsychology \& Behavior, 3(3), 483-499.

35. Ruthven, K. (2018). Instructional activity and student interaction with digital resources. In L. Fan, L. Trouche, C. Qi, S. Rezat, \& J. Visnovska (Eds.), Research on Mathematics Textbooks and Teachers' Resources (pp. 261-275). Cham: Springer.

36. Sala, N. M. (2016). Virtual Reality and Education: Overview Across Different Disciplines. In D.H. Choi, A. Dailey-Herbert, \& J. Simmons Estes (Eds.), Emerging Tools and Applications in Education (pp. 1-25). IGI Global.

37. Salinas, P. (2017). Augmented Reality: Opportunity for developing spatial visualization and learning calculus. In G. Kurubacak, \& H. Altinpulluk (Eds.), Mobile Technologies and Augmented Reality in Open Education (pp. 54-74). Hershey, PA: IGI Global. 
38. Sullivan, P., Mousley, J, \& R. Zevenbergen (2004). Describing Elements of Mathematics Lessons that Accommodate Diversity in Student Background. Proceedings of International Group for the Psychology of Mathematics Education, 28 ${ }^{\text {th }}$, Bergen, Norway, July 14-18, 2004. Vol. 4, 257-264. Retrieved from https://files.eric.ed.gov/fulltext/ED489650.pdf

39. United Nations Technology Innovations Lab (UNTIL) (Ed.) (2019). Inclusion and Diversity. Tech it or leave IT. https://until.un.org/sites/default/files/UNTIL_Inclusion_and_Diversity_FINAL.pdf

40. Wu, H., Lee, S.W., Chang, H., \& Liang, J. (2013). Current status, opportunities and challenges of augmented reality in education. Computers \& Education, 62, 41-49. doi:10.1016/j.compedu.2012.10.024

41. Yuen, S. C. Y., Yaoyuneyong, G., \& Johnson, E. (2011). Augmented reality: An overview and five directions for AR in education. Journal of Educational Technology Development and Exchange (JETDE), 4(1), 119-140.

42. Zhou, F., Duh, H.-L., \& Billinghurst, M. (2008). Trends in augmented reality traching, interaction and display: A review of ten years in ISMAR. Proceedings of the Mixed and Augmented Reality, ISMAR $7^{\text {th }}$ IEEE/ACM International Symposium, 193-202. Cambridge: IEEE.

\section{Acknowledgements}

We would like to highlight the great work of Andreas Janecek \& Patrick Pazour (Robimo GmbH) who developed the tasks in our, which we translated for this paper. 